\title{
Comparison of antioxidant effect and phenolic compounds in tropical fruits
}

\author{
Hee-Young Ahn ${ }^{1} \cdot$ Hyun-Dong $\mathrm{Cho}^{2} \cdot$ Young-Su Cho ${ }^{1}$ (D)
}

Received: 26 December 2019 / Accepted: 15 May 2020 / Published online: 25 May 2020

(c) Springer Nature Switzerland AG 2020

\begin{abstract}
There is a growing interest in consumption of tropical fruits because of their higher degree of antioxidant effects. In present study, we assessed the antioxidant potential as a functional food using popular three tropical fruits, such as litchi (Litchi chinensis Sonn.), rambutan (Nephelium lappaceum L.) and mangosteen (Garcinia mangostana L.). Tropical fruits were extracted in water, $70 \%$ ethanol and $70 \%$ methanol for $48 \mathrm{~h}$. Then, we analyzed the antioxidant effects of tropical fruit extracts using $\alpha$, $\alpha$-diphenyl- $\beta$-picrylhydrazyl (DPPH) radical scavenging, thiobarbituric acid reactive substance (TBARS) and reducing power assay. The DPPH radical scavenging and TBARS activities showed the highest degree in rambutan $70 \%$ ethanol extract compared with other tropical fruit extracts, as well as total phenolic and flavonoid contents were also highly identified in rambutan $70 \%$ ethanol extract. Furthermore, DPPH radical scavenging activity and reducing power was higher in the EtOAc fraction and the F-2 sub-fraction of rambutan $70 \%$ ethanol extract as compared with other fractions at the same concentrations. The EtOAc fraction and the F-2 sub-fraction had a large amount of phenols and flavonoids. The antioxidant effects of rambutan extract were closely associated with phenolic compound such as (-)-epicatechin. In conclusion, our results indicate that tropical fruits containing natural antioxidants might be used as supplements for human health, but this deserves further studies.
\end{abstract}

Keywords Tropical fruits · Antioxidant effects · Polyphenols $\cdot$ Flavonoids

\section{Introduction}

Recently, there is a growing interest in consumption of tropical fruits including litchi, mangosteen, rambutan, guava, mango, pineapple, wax apple and persimmon. Their sweet flavor can make consumer easy to eat every day, and abundant presence of dietary polyphenols such as, phenolic acids, flavonoids, tannins, coumarins, epicatechin and curcuminoids is anticipated to induce positive biological activity [1]. With recent commercial availability of tropical fruits in Korea, Japan and Europe, biological actions and therapeutic effects of tropical fruits have been studying by many researchers. Furthermore, phytochemicals in tropical fruits commonly comprise of flavonoids, phenolic acids, stilbenes and lignans [2]. Since they may have a broad-spectrum of biological effects arising from antioxidant and anti-inflammatory properties against obesity-induced oxidative stress and chronic inflammation, rich contents of phenolic compounds have been of extensive interest among researchers $[3,4]$.

Litchi is a tropical or subtropical fruit with a sweet flavor [5], and its pericarp (peel, rind, hull or ripe) contains a considerable amount of phenols, flavonoids, proanthocyanidin and procyanidin [6]. Rambutan, also known as rongroen, is a tropical fruit that is unique to the Southeast Asia [7]. In addition, it has polyphenols at a mean concentration of $1.64 \mathrm{mg} / 100 \mathrm{~g}$ (range $1.57-1.77 \mathrm{mg} / 100 \mathrm{~g}$ ) [1]. Mangosteen, known as "the queen of fruits", is also cultivated in

$\triangle$ Young-Su Cho, choys@dau.ac.kr| 'Department of Biotechnology, Dong-A University, 225 Gudeok-ro Seo-gu, Busan 49315, Korea. ${ }^{2}$ Department of Food Science, University of Arkansas, Fayetteville, AR, USA. 
the tropical rainforest of Southeast Asian countries, such as Indonesia, Malaysia, Sri Lanka, Philippines and Thailand [8]. Moreover, its pericarp has been used as a traditional medicine for the treatment of abdominal pain, skin infections and inflammations in Asian countries over the past centuries [9]. Numerous studies have reported that consumption of mangosteen is involved in the inhibition of oxidative damages caused by low-density lipoprotein (LDL) [5], anti-tumor, anti-bacterial and anti-oxidant effects [10]. Although these tropical fruits have been widely consumed as a functional food, the antioxidant capabilities have been reported using different analytical methods. Therefore, it is difficult to estimate the antioxidant activities of tropical fruits based on the comparison of literature studies.

Radical oxygen species (ROS) including superoxide $\left(\mathrm{O}_{2}^{-}\right)$, hydroxyl ( $\mathrm{HO} \mathrm{O}^{-}$, peroxyl (ROO), alkoxyl (RO) and nitric oxide (NO) are a natural by-product during biochemical metabolism in every aerobic organism [11]. However, development of chronic diseases is closely involved with unremoved ROS in molecular levels [11]. Especially, mammalian cell membrane lipids are vulnerable to oxidative reactions, and increase of ROS links to formation of malondialdehyde (MDA) which continuously causes oxidative stress and tissue damage. Once MDA is initiating to accumulate in tissues or biological fluids, it contributes to occur chronic diseases [12]. Although the antioxidant enzymes, such as superoxide dismutase, catalase and glutathione peroxidase can modulate the level of ROS in our body, consumption of natural antioxidant derived from food materials positively affect to reduce excessive ROS level [13-15]. Thus, in vitro and in vivo antioxidant studies on bioactive compounds and food ingredients to scavenge reactive oxygen can be helpful to improve human health [16].

The present study compared an anti-oxidant activity of water, ethanol and methanol extract of litchi, rambutan and mangosteen using different radical scavenging assay, and identified phenolic and flavonoid compounds in each extract, respectively. Compared to butylated hydroxytoluene (BHT), tropical fruit extracts efficiently induced antioxidant activity through various radical scavenging mechanisms. Our findings objectively elucidate the antioxidant potential of popular tropical fruit extracts in different extract condition, and could help facilitate the development of promising functional food material to reduce oxidative stress.

\section{Materials and methods}

\subsection{Chemicals}

a,a-Diphenyl- $\beta$-picrylhydrazyl (DPPH), thiobarbituric acid (TBA), BHT, (+) catechin, (-)-epicatechin, (-)-catechin gallate and Folin-Ciocalteu-s reagent were purchased from Sigma-Aldrich Chemical (St. Louis, MO). Other chemicals were of analytical grade.

\subsection{Preparation of tropical fruit extracts}

For the current experiment, we purchased commerciallyavailable fruits; these include litchi (Litchi chinensis Sonn.), rambutan (Nephelium lappaceum L.) and mangosteen (Garcinia mangostana L.). The pulp of tropical fruit was dried using dry incubator at $60^{\circ} \mathrm{C}$. Dried fruit samples were prepared into a powder with a cyclotec mill (Tecator, Hoganas, Sweden). A $100 \mathrm{~g}$ of powder samples were obtained from each fruit 3 times and then sequentially placed with $900 \mathrm{~mL}$ of distilled water, $70 \%$ ethanol (EtOH) and $70 \%$ methanol (MtOH) at room temperature for $48 \mathrm{~h}$. This was followed by a continuous mixing of the sample using a magnetic force stirrer. The mixture was filtered using a vacuum-assisted filter (Whatman No. 1 filter paper) (Toyo 2A; Toyo Roshi, Tokyo, Japan), which was followed by a vacuum-assisted evaporation of the solvent using a rotary evaporator at $40^{\circ} \mathrm{C}$ for $4 \mathrm{~h}$. Finally, the dried sample extract was obtained and then freeze-dried. Its yield was expressed as the percentage (\%). Dried tropical extracts were resolved by water, ethanol and methanol, respectively, and an in vitro antioxidant assay was performed using resolved extracts.

\subsection{Preparation rambutan fractions}

The rambutan powders were extracted using $70 \% \mathrm{EtOH}$. Dried EtOH extract of rambutan was dissolved in $200 \mathrm{~mL}$ of ethyl acetate (EtOAc), then which was mixed with $200 \mathrm{~mL}$ of distilled water. The mixture was partitioned onto EtOAc and aqueous layers. The EtOAc and water layers were separated from each other and then evaporated to dryness again. The resulting sample was weighed and the yield of each extract was determined accordingly.

The dried EtOAc extract $3.7 \mathrm{~g}$ was applied to opencolumn chromatogram $(35 \mathrm{~mm} \times 100 \mathrm{~mm})$ packed with a silica gel (Kiesel gel 60, 70-230 mesh; Merck, Dramstadt, Germany). The resulting sample was eluted using 100\% of dichloromethane, $100 \%$ of EtOAc, a mixture of EtOAc and $\mathrm{MtOH}(1: 1), 100 \%$ of $\mathrm{MtOH}$ and a mixture of $\mathrm{MtOH}$ and water (1:1) at a flow rate of $10 \mathrm{~mL} / \mathrm{min}$. Based on the retention factor (Rf) on thin layer chromatography (TLC), fractions were divided into 5 sub-fractions: fraction- 1 , $-2,-3,-4$ and $-5(F-1,-2,-3,-4$ and -5$)$. Silica gel $60 F_{254} 25$ aluminum sheets (Merck) were used as TLC plates. The chromatograms were developed up to $10 \mathrm{~cm}$ for $25 \mathrm{~min}$ using a mixture of chloroform and $\mathrm{MtOH}(5: 1, \mathrm{v} / \mathrm{v})$ at $25^{\circ} \mathrm{C}$. The 5 fractions were concentrated using a rotary vacuum 
evaporator and then used to analyze the antioxidant effects and reducing power of each fraction.

\subsection{Quantification of polyphenols}

The total amount of polyphenols was determined as previously described [17]. Briefly, $0.1 \%$ sample solution $10 \mathrm{~mL}$ was treated with Folin-Ciocalteu phenol reagent $2 \mathrm{~mL}$. After $5 \mathrm{~min}$, it was also treated with saturated sodium carbonate $\left(\mathrm{Na}_{2} \mathrm{CO}_{3}\right)$ solution $2 \mathrm{~mL}$, and placed on shaking incubator for $60 \mathrm{~min}$. Optimal density was measured at a wavelength of $725 \mathrm{~nm}$ using a UV mini 1240 UV-VIS spectrophotometer (Shimadzu, Kyoto, Japan). Then, samples and standard compound (chlorogenic acid) were treated to quantify polyphenols in tropical extracts. Phenolic contents were calculated by the standard curve plotted versus the concentration of the sample. The amount of polyphenols was expressed as the ratio of the amount of chlorogenic acid $(\mathrm{mg})$ to that of the sample $(100 \mathrm{~g})$.

\subsection{Quantification of flavonoids}

Flavonoid was quantified using the colorimeter method [18]. Briefly, $0.1 \%(\mathrm{w} / \mathrm{v})$ sample solution $(0.25 \mathrm{~mL})$ was mixed with a distilled water $(1.25 \mathrm{~mL})$, and $5 \% \mathrm{NaNO}_{2}$ solution $(0.75 \mathrm{~mL})$ in test tube. After $5 \mathrm{~min}$, the mixture was incubated with $10 \% \mathrm{AlCl}_{3} \cdot 6 \mathrm{H}_{2} \mathrm{O}(0.15 \mathrm{~mL})$ for $6 \mathrm{~min}$. Sequentially, $1 \mathrm{M} \mathrm{NaOH}(0.5 \mathrm{~mL})$ and $0.275 \mathrm{~mL}$ of distilled water were added to test tube. This was followed by the measurement of the absorbance of the mixture as compared with the blank at a wavelength of $510 \mathrm{~nm}$ using a UV mini 1240 UV-VIS spectrophotometer (Shimadzu, Tokyo, Japan). The amount of flavonoid was calculated using the

DPPH radical scavenging activity $(\%)=\left[1-\left(\right.\right.$ sample absorbance $\left._{528 \mathrm{~nm}}\right) /$ control absorbance $\left._{528 \mathrm{~nm}}\right] \times 100$

calibration curve $\left(\mathrm{R}_{2}=0.999\right)$ obtained using $(+)$-catechin hydrate as a standard $(2-200 \mu \mathrm{g} / \mathrm{mL})$. It was expressed as catechin equivalents $(\mathrm{mg}) / \mathrm{sample}(100 \mathrm{~g})$. All the extracts were analyzed in triplicate.

\subsection{Identification of bioactive compounds}

To identify bioactive compounds from the $\mathrm{EtOH}$ and EtOAc extracts, each extract and its fractions were filtered through a $0.2-\mu \mathrm{m}$ membrane filter (Millipore, Nylon, $170 \mathrm{~mm}$ ). This was followed by the analysis of the filtrate using the Agilent 1200 Series high-performance liquid chromatogram (HPLC) (Agilent Technologies, USA), the Zorbax eclipse plus $\mathrm{C}_{18}$ column $(5 \mu \mathrm{m} \times 4.5 \mathrm{~mm} \times 250 \mathrm{~mm})$ and the gradient solvent system. Thus, it was detected using the diode array detector (DAD) and the evaporating light scattering detector (ELSD) at a wavelength of $280 \mathrm{~nm}$, and a flow rate of $1.0 \mathrm{ml} / \mathrm{min}$ and a temperature of $30^{\circ} \mathrm{C}$ as previously described [19]. The temperature of evaporation using the ELSD was set at $40^{\circ} \mathrm{C}$. In addition, the pressure of nebulizing gas (N2) was set at 3.5 bar. The mobile phase was (A) water ( $0.1 \%$ trifluoroacetic acid) and (B) acetonitrile (0.1\% trifluoroacetic acid). The gradient elution was as follows: 0 min, 80\% A; $10 \mathrm{~min}, 80 \%$ A; $20 \mathrm{~min}, 50 \% \mathrm{~A} ; 25 \mathrm{~min}$, $0 \% \mathrm{~A} ; 35 \mathrm{~min}, 0 \% \mathrm{~A} ; 38 \mathrm{~min}, 100 \% \mathrm{~A} ; 48 \mathrm{~min}$ and $80 \% \mathrm{~A}$ (initial conditions). Then, it was held for 5 min before next injection. Individual compounds were identified through a comparison of the retention time (Rts) and UV spectral shapes of standard. Moreover, (+)-catechin, (-)-epicatechin and $(-)$ catechin gallate were used as a standard. The UV spectrum was scanned between 190 and $600 \mathrm{~nm}$. All the samples were prepared in methanol.

\subsection{DPPH radical scavenging assay}

The degree of antioxidant effects was determined based on the radical scavenging activity of the sample solution, for which $16 \mathrm{mg}$ of DPPH was dissolved in $100 \mathrm{~mL}$ of EtOH as a concentration of $0.4 \mathrm{mM}$. The sample was filtered through the Whatman filter paper No. 2 (Toyo Roshi, Tokyo, Japan). This was followed by the addition of $2 \mathrm{~mL}$ of DPPH to the $1 \mathrm{~mL}$ of samples at varying concentrations of 0,250 and $500 \mu \mathrm{g} / \mathrm{mL}$ (tropical fruit extracts) and $100 \mu \mathrm{g} / \mathrm{mL}$ (rambutan fractions). The mixture was incubated at room temperature for $30 \mathrm{~min}$, which was followed by the measurement of the absorbance a wavelength of $528 \mathrm{~nm}$ using the UV mini 1240 UV-VIS spectrophotometer (Shimadzu). In the current experiment, BHT 100 or $500 \mu \mathrm{g} / \mathrm{mL}$ was used as a positive control. The percentage of the antioxidant activity was expressed based on the following formula:

\subsection{Thiobarbituric acid reactive substance (TBARS) assay}

Inhibitory effect of tropical fruit extracts on linoleic acid (LA) peroxidation was determined by TBARS assay [20]. Two $\mathrm{mL}$ of extracts $(0.1 \%, \mathrm{w} / \mathrm{v})$ was mixed with $2 \mathrm{~mL}$ of $\mathrm{LA}(2.5 \mathrm{mg} / \mathrm{mL}$ in EtOH), $4 \mathrm{~mL}$ of $0.2 \mathrm{M}$ phosphate buffer $(\mathrm{pH} 7.0)$ and $2 \mathrm{~mL}$ of deionized distilled water. This was followed by the incubation at $40^{\circ} \mathrm{C}$ in the dark place for 7 days. Then, $0.5 \mathrm{~mL}$ of solution was mixed with $0.25 \mathrm{~mL}$ of $35 \%$ trichloroacetic acid and $0.5 \mathrm{~mL}$ of $0.75 \%$ aqueous TBA. Thus, the mixture was heated in a boiling water bath for $15 \mathrm{~min}$ to develop color, and then treated with $0.5 \mathrm{~mL}$ of $70 \%$ trichloroacetic acid. After $20 \mathrm{~min}$, it was centrifuged at $3000 \mathrm{rpm}$ for $15 \mathrm{~min}$ to isolate 
micro-particles. This was followed by the measurement of the absorbance of the supernatant at a wavelength of $532 \mathrm{~nm}$ using the UV mini 1240 UV-VIS spectrophotometer (Shimadzu). Deionized distilled water was substituted for the extract in the blank sample. The inhibitory effects against the lipid peroxidation in LA was calculated based on the following formula: extraction yield was outstanding in water solvent (30.96\%) compared with $\mathrm{EtOH}(22.13 \%)$ and $\mathrm{MeOH}$ (18.29\%). However, mangosteen extracts did not show notable difference in water (30.42\%), $\mathrm{MeOH}(30.08 \%)$ and $\mathrm{EtOH}(27.38 \%)$ solvents.

Inhibition ratio $(\%)=[1-($ sample absorbance - blank absorbance $) /($ control absorbance - blank absorbance $)] \times 100$

\subsection{Reducing power assay}

The reducing power was measured with the slightly modified method of Oyaizu [21]. The fractions or extracts $(0.75 \mathrm{~mL})$ were mixed with $0.2 \mathrm{M}$ sodium phosphate buffer $(\mathrm{pH} 6.6) 1.25 \mathrm{~mL}$ and $1 \%(\mathrm{w} / \mathrm{v})$ potassium ferricyanide $\left(\mathrm{K}_{3} \mathrm{Fe}(\mathrm{CN})_{6}\right) 1.25 \mathrm{~mL}$ at varying concentrations ranging from 10 to $1000 \mu \mathrm{g} / \mathrm{mL}$. The mixture was shaken vigorously at $50^{\circ} \mathrm{C}$ for $20 \mathrm{~min}$. Following this, it was treated with trichloroacetic acid $(10 \%, \mathrm{w} / \mathrm{v}) 1.25 \mathrm{~mL}$ and then centrifuged at $3000 \mathrm{rpm}$ for $20 \mathrm{~min}$. The supernatant $(2.5 \mathrm{~mL})$ was collected and then mixed with a distilled water $2.5 \mathrm{~mL}$ and $0.5 \%$ ferric chloride $\left(\mathrm{FeCl}_{3}\right)$ $0.5 \mathrm{~mL}$. Then, the mixture was shaken vigorously at room temperature for $10 \mathrm{~min}$. After the color development, the absorbance was measured using the UV mini 2450 UV-VIS spectrophotometer (Shimadzu) at a wavelength of 700 against reagent blank.

\section{Results}

\subsection{Extraction yield of tropical fruit extracts}

To compare the effectiveness of extract condition, extraction yield of tropical fruit extract was identified using various solvent including water, $\mathrm{EtOH}$ and $\mathrm{MeOH}$ (Table 1). Among litchi extracts, the water extract showed the higher extraction yield (37.58\%) compared to $\mathrm{MeOH}(22.41 \%)$ and $\mathrm{EtOH}(18.37 \%)$. In rambutan,

Table 1 The percentage yield of water, ethanol and methanol extracts of tropical fruits

\begin{tabular}{llll}
\hline Extracts & \multicolumn{2}{l}{ Percentage yield (\%) } \\
\cline { 2 - 4 } Extracts & Litchi & Rambutan & Mangosteen \\
\hline Water & 37.58 & 30.96 & 30.42 \\
EtOH & 18.37 & 22.13 & 27.38 \\
MtOH & 22.41 & 18.29 & 30.08 \\
\hline
\end{tabular}

EtOH Ethanol, MtOH methanol

\subsection{Comparison of DPPH radical scavenging activity in tropical fruit extracts}

Since it is useful in analyzing short-term anti-oxidant effects, DPPH assay is commonly used to determine the antioxidant activity of natural products $[22,23]$. To compare antioxidant activity of tropical fruit extracts, DPPH radical scavenging was measured for water, EtOH and $\mathrm{MeOH}$ extracts of litchi, rambutan and mangosteen (Fig. 1). Treatment of $500 \mu \mathrm{g} / \mathrm{mL}$ of rambutan EtOH extract (95.46\%) and mangosteen MtOH extract (93.24\%) had a higher capacity of DPPH radical scavenging activity in comparison with other tropical fruit extracts. Especially, $500 \mu \mathrm{g} / \mathrm{mL}$ of rambutan EtOH extract indicated similar degree of DPPH radical scavenging activity with same concentration of BHT, synthetic antioxidant (92.58\%). Mangosteen $\mathrm{EtOH}$ (92.79\%) and $\mathrm{MeOH}$ extract (93.24\%) also showed high levels of DPPH radical scavenging activity at the concentration of $500 \mu \mathrm{g} / \mathrm{mL}$. Compared with EtOH and $\mathrm{MeOH}$ extracts at the concentration of $250-500 \mu \mathrm{g} /$ $\mathrm{mL}$, antioxidant activities of water extracts were higher in litchi (47.27\%), however, the levels were lower in rambutan (59.92\%) and mangosteen (33.64\%). These findings demonstrate that EtOH extracts of rambutan and mangosteen were potential resource for antioxidant functional food.

\subsection{Comparison of linoleic acid (LA) peroxidation inhibitory effect in tropical fruit extracts}

Antioxidant activity includes an inhibitory effect against ferrous iron $\left(\mathrm{Fe}^{2+}\right)$-catalyzed lipid peroxidation due to ferric thiobarbituric acid (TBA) arising from in vivo membrane damage [24]. In present study, we further studied inhibition effect of tropical fruit extracts on LA peroxidation to identify antioxidant effect on lipid peroxidation. After $24 \mathrm{~h}$ incubation, a rapid increase of peroxidized LA was observed in both of control and fruit extract treated group, and it was maintaining until 7 days (data not shown). LA peroxidation inhibition rate indicated that EtOH extracts of litchi, rambutan and mangosteen had a higher degree of inhibition rate $39.95 \%, 52.19 \%$ and $41.22 \%$, respectively 
Fig. 1 The DPPH radical scavenging activity of water (W), ethanol (E) and methanol (M) extracts of tropical fruits. BHT Butylated hydroxytoluene, DPPH a,a-diphenyl$\beta$-picrylhydrazyl. Values are mean \pm SD (SD: standard deviation) $(n=3)$
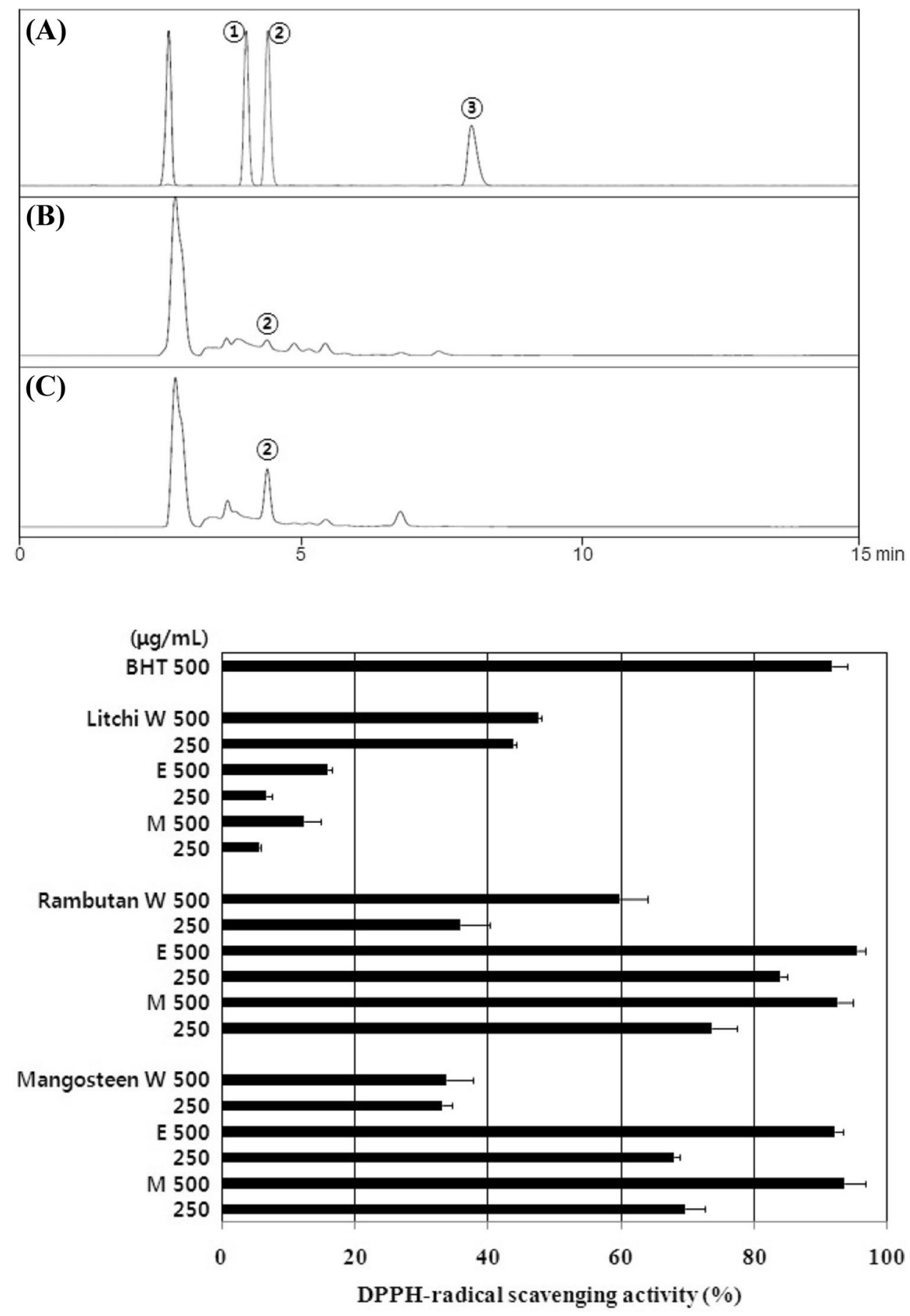

Fig. 2 The degree of antioxidant effects of water, ethanol and methanol extracts of tropical fruits based on the inhibition of linoleic acid peroxidation thiobarbituric acid assay. BHT Butylated hydroxytoluene. Values are mean \pm SD (SD: standard deviation) $(n=3)$ as compared with each water and $\mathrm{MeOH}$ extracts (Fig. 2). Moreover, BHT had the highest degree of antioxidant effects (Fig. 2). Although synthetic antioxidant BHT indicated highest LA peroxidation inhibitory effect (83.61\%), rambutan EtOH extract were higher antioxidant activity on LA peroxidation than other tropical fruit extracts. This result indicates that EtOH extract of rambutan is outstanding functional food materials to prevent lipid peroxidation.

\subsection{Total amount of polyphenols and flavonoids}

In order to identify whether or not contents of polyphenols and flavonoids in tropical fruit extracts are related with antioxidant effect, we further analyzed total amount of phenolic and flavonoid compounds in water, EtOH and $\mathrm{MeOH}$ extracts of tropical fruit (Tables 2, 3). Litchi, rambutan and mangosteen EtOH extracts showed 9.97, 23.50 and $20.99 \mathrm{mg}$ of total phenolic contents, and 0.64, 3.10 and 
Table 2 Total amount of phenols from water, ethanol and methanol extracts of tropical fruits

\begin{tabular}{llcr}
\hline Extracts & \multicolumn{2}{l}{ Total amount of phenols $(\mathrm{mg} / 100 \mathrm{~g}$ dry wt) } \\
\cline { 2 - 4 } Extracts & \multicolumn{1}{l}{ Litchi } & Rambutan & \multicolumn{1}{c}{ Mangosteen } \\
\hline Water & $2.00 \pm 0.01$ & $11.99 \pm 0.01$ & $5.99 \pm 0.01$ \\
EtOH & $9.97 \pm 0.05$ & $23.50 \pm 0.01$ & $20.99 \pm 0.01$ \\
MtOH & $5.98 \pm 0.02$ & $19.00 \pm 0.01$ & $19.01 \pm 0.01$ \\
\hline
\end{tabular}

Values are mean $\pm S D(S D$ : standard deviation) $(n=3)$

EtOH Ethanol, MtOH methanol

Table 3 The amount of flavonoids from water, ethanol and methanol extracts of tropical fruits

\begin{tabular}{llcc}
\hline Extracts & \multicolumn{2}{l}{ Total amount of flavonoids $(\mathrm{mg} / 100 \mathrm{~g}$ dry wt) } \\
\cline { 2 - 4 } & Litchi & Rambutan & Mangosteen \\
\hline Water & $0.20 \pm 0.01$ & $1.45 \pm 0.04$ & $1.98 \pm 0.03$ \\
EtOH & $0.64 \pm 0.01$ & $3.10 \pm 0.10$ & $6.08 \pm 0.14$ \\
MtOH & $0.42 \pm 0.01$ & $2.31 \pm 0.08$ & $4.31 \pm 0.12$ \\
\hline
\end{tabular}

Values are mean $\pm S D$ (SD: standard deviation) $(n=3)$

EtOH Ethanol, MtOH methanol

$6.08 \mathrm{mg}$ of total flavonoid contents in $100 \mathrm{~g}$ of dry weight extract, respectively. The $\mathrm{MeOH}$ extract of litchi, rambutan and mangosteen indicated 5.98, 19.00 and $19.01 \mathrm{mg}$ of total phenolic contents, and $0.42,2.31$ and $4.31 \mathrm{mg}$ of total flavonoid contents in $100 \mathrm{~g}$ of dry weight extract, respectively. The water extracts of tropical fruit had a slightly smaller amount of phenols and flavonoids as compared with the $\mathrm{EtOH}$ or $\mathrm{MtOH}$ extracts. These results suggest that antioxidant effect of tropical fruit extracts are related with contents of phenolics and flavonoids.

\subsection{Identification of bioactive compounds from extracts of rambutan EtOAc fraction and its sub-fractions}

In present study, rambutan EtOH extract had outstanding antioxidant potential compared to other tropical fruit extracts. In EtOAc fraction of rambutan and its sub-fractions, the percentage yield was demonstrated by $10.9 \%$ (794 $\mathrm{mg})$ in the F-1, 14.0\% (1018 mg) in the F-2, 3.4\% $(246 \mathrm{mg})$ in the $\mathrm{F}-3,33.0 \%$ (2398 $\mathrm{mg}$ ) in the F-4 and $12.0 \%$ (868 mg) in the F-5 on silica gel open-column chromatography. The total weight and yield were $5324 \mathrm{mg}$ and $73.3 \%$, respectively (data not shown).

To increase utilization of rambutan extract as a functional food material, we further analyzed bioactive compounds in rambutan EtOH extract, EtOAc fraction and its sub-fractions (Fig. 3, Table 4). The total amount of phenolic and flavonoid contents in EtOAc fraction of rambutan was

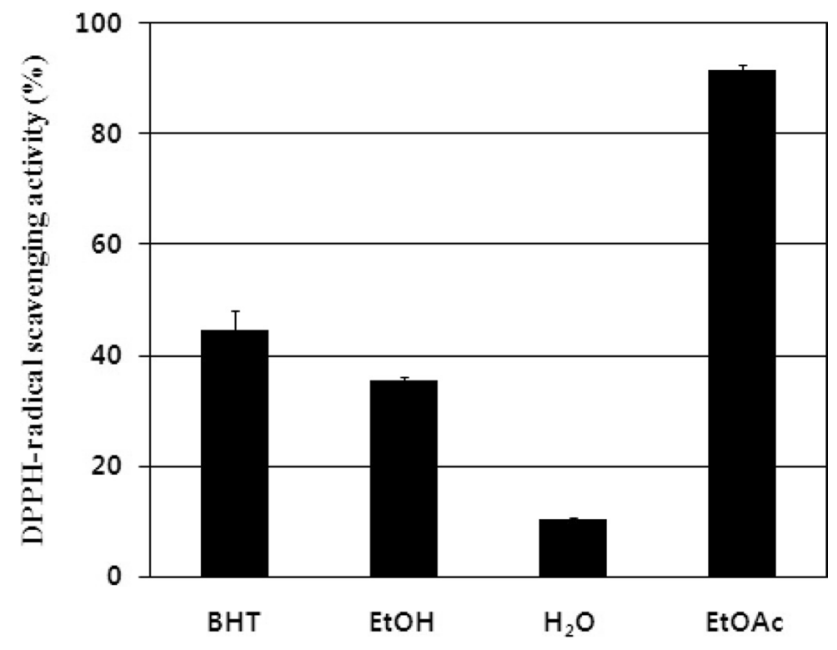

Fig. 3 The high-performance liquid chromatograms of the standard (A), ethyl acetate extract (B) and fractions of ethanol extract (C) of rambutan. EtOAc Ethyl acetate, ND not determined. Peaks: (1), (+)-catechin; (2), (-)-epicatechin; (3), (-)-catechin gallate

Table 4 The a,a-diphenyl- $\beta$-picrylhydrazyl radical scavenging activity and the total amount of phenols and flavonoids from butylated hydroxytoluene extract, ethyl acetate extract and fractions of ethanol extract of rambutan

\begin{tabular}{lclc}
\hline & $\begin{array}{l}\text { DPPH radical scav- } \\
\text { enging activity (\%) } \\
(100 \mu \mathrm{g} / \mathrm{mL})\end{array}$ & Phenols $(\mathrm{mg} / \mathrm{g})$ & Flavonoids $(\mathrm{mg} / \mathrm{g})$ \\
\hline BHT & $78.37 \pm 0.11$ & ND & ND \\
EtOAc & $91.66 \pm 0.94$ & $367.8 \pm 0.50$ & $24.84 \pm 0.14$ \\
F-1 & $7.24 \pm 1.19$ & $150.3 \pm 1.60$ & $20.8 \pm 1.19$ \\
F-2 & $98.49 \pm 0.07$ & $661.9 \pm 1.10$ & $73.7 \pm 1.17$ \\
F-3 & $94.34 \pm 0.08$ & $352.3 \pm 0.70$ & $31.1 \pm 0.15$ \\
F-4 & $86.70 \pm 1.27$ & $353.9 \pm 0.70$ & $47.0 \pm 0.40$ \\
F-5 & $92.25 \pm 1.23$ & $357.5 \pm 1.50$ & $37.5 \pm 1.10$ \\
\hline
\end{tabular}

Values are mean \pm SD (SD: standard deviation) $(n=3)$

$D P P H$ a,a-Diphenyl- $\beta$-picrylhydrazyl, BHT butylated hydroxytoluene, EtOAc ethyl acetate, ND not determined

$367.8 \pm 0.50$ and $24.84 \pm 0.14 \mathrm{mg} / \mathrm{g}$, respectively (Table 4). In addition, its sub-fractions including F-1, F-2, F-3, F-4 and F-5 showed $150.3 \pm 1.60,661.9 \pm 1.10,352.3 \pm 0.70$, $353.9 \pm 0.70$ and $357.5 \pm 1.50 \mathrm{mg} / \mathrm{g}$ of total phenolic contents, and $20.8 \pm 1.19,73.7 \pm 1.17,31.1 \pm 0.15,47.0 \pm 0.40$ and $37.5 \pm 1.10$ of flavonoid contents, respectively (Table 4).

A large amount of phenols was also identified by HPLC-PDA analysis in EtOAc fraction of rambutan and F-2 sub-fraction. Compared to standard peak, content of (-)-epicatechin (retention time [Rt] $4.316 \mathrm{~min}$ ) was verified in EtOAc fraction $(29.2 \mathrm{mg} / \mathrm{g}), \mathrm{F}-2(70.4 \mathrm{mg} / \mathrm{g})$ and F-3 $(10.4 \mathrm{mg} / \mathrm{g})$ sub-fractions, respectively (Fig. 3). However, 


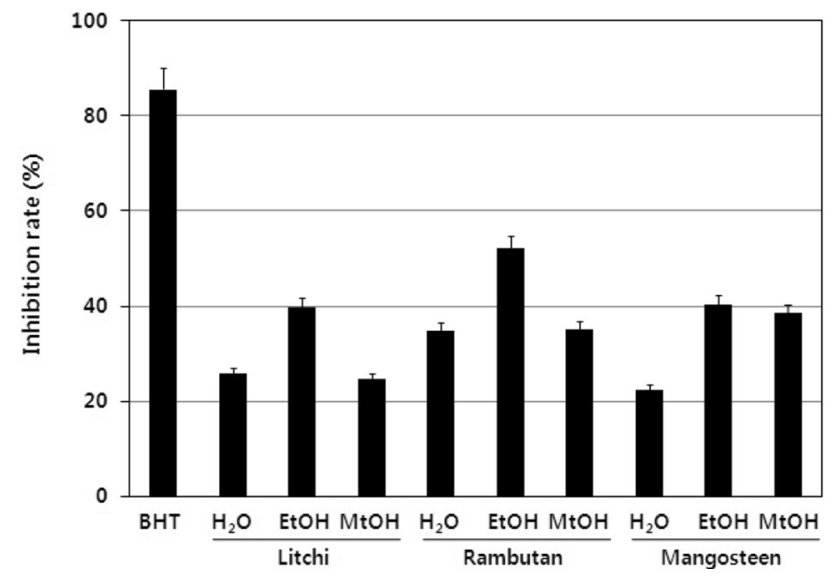

Fig. 4 The degree of reducing power of butylated hydroxytoluene, ethanol and ethyl acetate extracts and fractions of rambutan extract. BHT Butylated hydroxytoluene, EtOH ethanol, EtOAc ethyl acetate. Values are mean \pm SD (SD: standard deviation) $(n=3)$

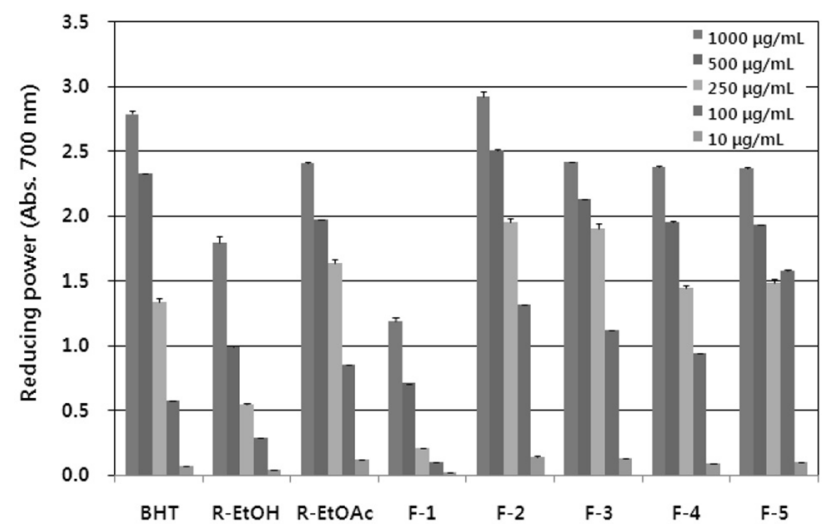

Fig. 5 The DPPH radical scavenging activity of water and ethyl acetate fractions of $70 \%$ ethanol extract of rambutan. DPPH,a,aDiphenyl- $\beta$-picrylhydrazyl, BHT butylated hydroxytoluene, EtOH ethanol, EtOAc ethyl acetate. Values are mean \pm SD (SD: standard deviation) $(\mathrm{n}=3)$

(-)-epicatechin analogues, such as (+)-catechin and $(-)$-catechin gallate, were not identified in EtOH extract, EtOAc fraction and its sub-fractions. These results suggest that (-)-epicatechin is one of the major phenolic compound in rambutan EtOH extract, and F-2 fraction had a highest amount of phenolic and flavonoid contents in rambutan EtOAc sub-fractions.

\subsection{Antioxidant activity of rambutan EtOAc fraction and its sub-fractions}

There was a significant positive correlation between the reducing power and concentrations of EtOH extract, EtOAc fraction and its sub-fractions (Fig. 4). As shown in Fig. 5, the F-2 fraction of the EtOAc extract had the highest degree of reducing power. Of note, the degree of DPPH radical scavenging effects of EtOAc fraction, F-2, $-3,-4$ and -5 sub-fractions were higher as compared with the BHT with no respect to concentrations (Table 4). In addition, EtOAc fraction showed higher DPPH radical scavenging activity as compared with the $\mathrm{BHT}$ at the same concentration of $100 \mu \mathrm{g} / \mathrm{mL}$ (Fig. 5). The F-1 fraction showed the lowest degree of DPPH radical scavenging effect compared with the BHT. These results indicate that rambutan EtOAc $\mathrm{F}-2$ sub-fraction is a potential functional food material for antioxidant activity.

\section{Discussion}

Since tropical fruits are rich source of antioxidant compounds, recent studies have concentrated their outstanding health improving activity. In the industrial view point, extraction yield is an important condition to processing food materials. According to Wang et al., the yield of crude EtOH extract of mature Baila litchi exceeded $22.0 \%$, and $60 \%$ of component were water-soluble and the remaining $40 \%$ of which were $\mathrm{EtOH}$ - and acetone-soluble [25]. In addition, Chomnawang et al. reported that the yield (\%) of EtOH extract against the pericarps of Garcinia mangostana was $15.63 \%$ [26]. In current study, although water extract of litchi, rambutan and mangosteen was identified to have highest extraction yield, EtOH extract showed similar tendency with previous studies in terms of antioxidant effect and extraction yield. These data indicate that water extract of litchi, rambutan and mangosteen are advantageous to develop ordinary food or drink, however EtOH extracts are best extract condition to process tropical fruits as a functional food material.

In the current study, the amount of polyphenols and flavonoids were highest in the EtOH extract of litchi, rambutan and mangosteen compared to their water and $\mathrm{MeOH}$ extract. The total amount of phenols in litchi, rambutan and mangosteen was reported to contain by 3.35, 1.39 and $1.64 \mathrm{mg} / 100 \mathrm{~g}$, respectively [1]. As compared with a previous published studies [1], our results showed a significantly larger amount of phenols were contained in litchi, rambutan and mangosteen. There are considerable amounts of polyphenols in the pericap of litchi; these include condensed tannins (polymeric proanthocyanidins), epicatechin and procyanidin A2 [25, 27]. Litchi and rambutan belong to the Sapindaceae family, and both fruits share similar appearances, flavor, pericarp color and juicy aril. It is presumed that the extract of rambutan shared similar chemical properties with the pericap of litchi. According to Sun et al., the fractions of EtOAc had a significantly larger amount of phenols $(1.475 \mathrm{mg} \mathrm{GAE} / \mathrm{g}$ FW) as compared with those of $n$-butanol (1.213 mg GAE/g 
FW) and water (0.778 mg GAE/g FW) [28]. Furthermore, Sun et al. showed that the pericaps of litchi and rambutan contained (-)-epicatechin at concentrations of 1655 and $75 \mu \mathrm{g} / \mathrm{g} \mathrm{FW}$, respectively. Moreover, these authors also noted that (-)-epicatechin is present in green tea and other tropical plants, and its antioxidant effects have been well described in the literature [28]. In present study, contents of (-)-epicatechin were identified by HPLC in rambutan $\mathrm{F}-2$ and $\mathrm{F}-4$ fractions which showed outstanding antioxidant activity on DPPH radical scavenging and reducing power.

Flavonoids are phenols that are abundantly present in foods. To date, more than 4000 different types of flavonoids have been identified. They are known as one of major constituents of the extract of mature or premature litchi; they have been reported to have a strong antioxidant effect [29]. The amount of flavonoids was the largest in the EtOH extract of litchi, rambutan and mangosteen, and the smallest in the water extracts. Previous studies have reported that mangosteen and Mao Luang had a total amount of flavonoids of 54.1 and $397.9 \mathrm{mg} / 100 \mathrm{~g}$, respectively $[1,30]$. This is also accompanied by a report showing not only that 15 Mao Luang cultivars contained three types of flavonoids (catechin, procyanidin B1 and procyanidin B2) but also that they were composed of such flavonoid compounds. Furthermore, the amount of catechin contained in 15 cultivars varied, ranging from 73.39 to $316.22 \mathrm{mg} / 100 \mathrm{~g}$ (fresh weight) [30]. Therefore, a large amount of phenols and flavonoids from the EtOAc fraction and F-2 sub-fraction of the EtOH extract of rambutan might be closely involved in their antioxidant effects.

The antioxidant effects based on DPPH radical scavenging activity might arise from the electron or hydrogen donating ability [31]. A number of studies have reported that natural antioxidants, such as tocopherol, phenols, glutathione and zinc, have a higher degree of antioxidant effects to indicate strong free radical scavenging activity [32]. It has been also reported that synthetic antioxidant BHT had a higher degree of effects in scavenging DPPH free radicals [33]. This is in agreement with our results showing that its degree reached the highest level in the $\mathrm{EtOH}$ extract of rambutan at a concentration of BHT of $500 \mu \mathrm{g} / \mathrm{mL}$. The degree of the antioxidant effects was the highest in $\mathrm{EtOH}$ extract of rambutan compared with other tropical fruit extracts. In addition, we also found that the EtOAc fraction had a higher degree of antioxidant effect as compared with the BHT at the same concentration of $100 \mu \mathrm{g} / \mathrm{mL}$. Despite the same concentrations, however, the degree of antioxidant effect was lower in the water fraction of EtOH extract of rambutan as compared with $\mathrm{BHT}$ or EtOAc one. It has also been previously shown that the EtOAc extract of rambutan peel had the largest amount of polyphenols and the highest degree of effects in scavenging free radicals [34]. Previous studies have shown that the EtOH extract of mangosteen had the highest degree of antioxidant effect of the four extracts (water, 50\% EtOH, $95 \% \mathrm{EtOH}$ and EtOAc ones) in a DPPH radical scavenging model $[26,35]$. These results showed similar tendency in phenolic and flavonoid contents of tropical fruit extracts. Therefore, the DPPH radical scavenging activity in $70 \%$ EtOH extract of rambutan mainly arises from the EtOAc fraction and F-2 sub-fraction containing higher (-)-epicatechin, polyphenol and flavonoid contents.

The effects of polyunsaturated fatty acids, such as $L A$, methyl $L A$ and arachidonic acid, in inhibiting lipid peroxidation have been studied to identify antioxidants [36]. We found that the EtOH extracts of litchi, rambu$\tan$ and mangosteen had a higher degree of antioxidant effects in inhibiting LA peroxidation as compared with other extracts. According to another study, there was a marked inhibition in the LA oxidation by the EtOHsoluble extracts of all Philippine fruits and vegetables. Of these, mangosteen had the highest degree of antioxidant activity effect [37].

It is generally known that the antioxidant effects of bioactive compounds are closely associated with their reducing power arising from an ability to donate electrons [38]. We found a significant positive correlation between the total reducing power and concentrations of EtOH extract and EtOAc fraction and their sub-fractions. We also showed that the F-2 sub-fraction had the highest degree of reducing power. Of note, it was higher as compared with the BHT with no respect to concentrations. Presumably, this might be related with rich phenolic and flavonoid compounds in F-2 sub-fraction. Furthermore, it followed the same descending order as that of DPPH radical scavenging activity. As compared with the extracts of rich hull and Sonchus oleraceus L., however, the water extract had a relatively lower degree of reducing power $[39,40]$. This suggests that there is a significant correlation between the degree of antioxidant effect and that of reducing power of sub-fractions of rambutan, which is in agreement with previous published studies showing that the EtOAc extract had a relatively higher degree of reducing power.

To summarize, our results are as follows: (1) DPPH radical scavenging activity and reducing power occurred in a concentration-dependent manner. (2) The degree of DPPH free radical scavenging activity and reducing power was higher in the EtOAc fraction and the F-2 as compared with other fractions at the same concentrations. (3) The EtOAc extract of $70 \% \mathrm{EtOH}$ one of rambutan had a large amount of phenols and flavonoids. Its antioxidant effects originated from the F- 2 fraction. This indicates that the antioxidant effects of rambutan extract are closely associated 
with phenols such as (-)-epicatechin. Based on the above results, it can therefore be concluded that tropical fruits containing natural antioxidants might be used as supplements for human health. But this deserves further studies on optical method of extraction.

Acknowledgements The current study was supported by the Dong-A University Research Fund.

\section{Compliance with ethical standards}

Conflict of interest The authors declare that they have no conflict of interest.

\section{References}

1. Gorinstein S, Zemser M, Haruenkit R, Chuthakorn R, Grauer F, Martin-Belloso O, Trakhtenberg S (1999) Comparative content of total polyphenols and dietary fiber in tropical fruits and persimmon. J Nutr Biochem 10(6):367-371

2. Scalbert A, Williamson $G$ (2000) Dietary intake and bioavailability of polyphenols. J Nutr 130(8S Suppl):2073S-2085S

3. Siriwardhana N, Kalupahana NS, Cekanova M, LeMieux M, Greer B, Moustaid-Moussa N (2013) Modulation of adipose tissue inflammation by bioactive food compounds. J Nutr Biochem 24(4):613-623

4. Pandey KB, Rizvi SI (2009) Plant polyphenols as dietary antioxidants in human health and disease. Oxid Med Cell Longev 2(5):270-278

5. Das AK, Rajkumar V, Nanda PK, Chauhan P, Pradhan SR, Biswas S (2016) Antioxidant efficacy of litchi (Litchi chinensis Sonn.) pericarp extract in sheep meat nuggets. Antioxidants 5(2):16

6. Lv Q, Luo F, Zhao X, Liu Y, Hu G, Sun C, Li X, Chen K (2015) Identification of proanthocyanidins from litchi (Litchi chinensis Sonn.) pulp by LC-ESI-Q-TOF-MS and their antioxidant activity. PLoS ONE 10(3):e0120480

7. Ong PK, Acree TE, Lavin EH (1998) Characterization of volatiles in rambutan fruit (Nephelium lappaceum L.). J Agric Food Chem 46(2):611-615

8. Pedraza-Chaverri J, Cárdenas-Rodríguez N, Orozco-lbarra M, Pérez-Rojas JM (2008) Medicinal properties of mangosteen (Garcinia mangostana). Food Chem Toxicol 46(10):3227-3239

9. Gutierrez-Orozco F, Failla ML (2013) Biological activities and bioavailability of mangosteen xanthones: a critical review of the current evidence. Nutrients 5(8):3163-3183

10. Jung HA, Su BN, Keller WJ, Mehta RG, Kinghorn AD (2006) Antioxidant xanthones from the pericarp of Garcinia mangostana (Mangosteen). J Agric Food Chem 54(6):2077-2082

11. Fan Z, Xu H (2020) Recent progress in the biological applications of reactive oxygen species-responsive polymers. Polym Rev 60(1):114-143

12. Gutteridge JM (1995) Lipid peroxidation and antioxidants as biomarkers of tissue damage. Clin Chem 41(12 Pt 2):1819-1828

13. Finley JW, Kong AN, Hintze KJ, Jeffery EH, Ji LL, Lei XG (2011) Antioxidants in foods: state of the science important to the food industry. J Agric Food Chem 59(13):6837-6846

14. de Oliveira e Silva AM, Vidal-Novoa A, Batista-González AE, Pinto JR, Portari Mancini DA, Reina-Urquijo W, Mancini-Filho J (2012) In vivo and in vitro antioxidant activity and hepatoprotective properties of polyphenols from Halimeda opuntia (Linnaeus) Lamouroux. Redox Rep 17(2):47-53

15. Cui K, Luo X, Xu K, Ven Murthy MR (2004) Role of oxidative stress in neurodegeneration: recent developments in assay methods for oxidative stress and nutraceutical antioxidants. Prog Neuropsychopharmacol Biol Psychiatry 28(5):771-799

16. Spormann TM, Albert FW, Rath $T$, Dietrich $H$, Will F, Stockis JP, Eisenbrand G, Janzowski C (2008) Anthocyanin/polyphenolicrich fruit juice reduces oxidative cell damage in an intervention study with patients on hemodialysis. Cancer Epidemiol Biomark Prev 17(12):3372-3380

17. Tosun M, Ercisli S, Sengul M, Ozer H, Polat T, Ozturk E (2009) Antioxidant properties and total phenolic content of eight Salvia species from Turkey. Biol Res 42(2):175-181

18. Ogbeide ON, Parvez M (1991) A simple colorimetric quantification of flavonoids in the flowers of Lonchocarpus cyanescens genus: Lonchocarpus. Plant Foods Hum Nutr 41(3):233-239

19. Wang J, Liu B, Xiao Q, Li H, Sun J (2014) Cloning and expression analysis of litchi (Litchi chinensis Sonn.) polyphenol oxidase gene and relationship with postharvest pericarp browning. PLoS ONE 9(4):e93982

20. Ohkawa H, Ohishi N, Yagi K (1979) Assay for lipid peroxides in animal tissues by thiobarbituric acid reaction. Anal Biochem 95(2):351-358

21. Moukette BM, Pieme AC, Biapa PC, Njimou JR, Stoller M, Bravi $M$, Yonkeu Ngogang J (2015) In vitro ion chelating, antioxidative mechanism of extracts from fruits and barks of Tetrapleura tetraptera and their protective effects against fenton mediated toxicity of metal ions on liver homogenates. Evid Based Complement Altern Med 2015:423689

22. Xie J, Schaich KM (2014) Re-evaluation of the 2,2-diphenyl-1-picrylhydrazyl free radical (DPPH) assay for antioxidant activity. J Agric Food Chem 62(19):4251-4260

23. Loganayaki N, Siddhuraju P, Manian S (2013) Antioxidant activity and free radical scavenging capacity of phenolic extracts from Helicteres isora L. and Ceiba pentandra L. J Food Sci Technol 50(4):687-695

24. Oboh G, Olabiyi AA, Akinyemi AJ (2013) Inhibitory effect of aqueous extract of different parts of unripe pawpaw (Carica papaya) fruit on $\mathrm{Fe}^{2+}$-induced oxidative stress in rat pancreas in vitro. Pharm Biol 51(9):1165-1174

25. Wang X, Yuan S, Wang J, Lin P, Liu G, Lu Y, Zhang J, Wang W, Wei Y (2006) Anticancer activity of litchi fruit pericarp extract against human breast cancer in vitro and in vivo. Toxicol Appl Pharmacol 215(2):168-178

26. Chomnawang MT, Surassmo S, Nukoolkarn VS, Gritsanapan W (2007) Effect of Garcinia mangostana on inflammation caused by Propionibacterium acnes. Fitoterapia 78(6):401-408

27. Li W, Liang H, Zhang MW, Zhang RF, Deng YY, Wei ZC, Zhang Y, Tang XJ (2012) Phenolic profiles and antioxidant activity of litchi (Litchi chinensis Sonn.) fruit pericarp from different commercially available cultivars. Molecules 17(12):14954-14967

28. Sun J, Su W, Peng H, Zhu J, Xu L, Bruñá NM (2010) Two endogenous substrates for polyphenoloxidase in pericarp tissues of postharvest rambutan fruit. J Food Sci 75(6):C473-C477

29. Su D, Zhang R, Hou F, Zhang M, Guo J, Huang F, Deng Y, Wei Z (2014) Comparison of the free and bound phenolic profiles and cellular antioxidant activities of litchi pulp extracts from different solvents. BMC Complement Altern Med 14:9

30. Ghasemzadeh A, Jaafar HZE, Baghdadi A, Tayebi-Meigooni A (2018) Alpha-mangostin-rich extracts from mangosteen pericarp: optimization of green extraction protocol and evaluation of biological activity. Molecules 23(8):1852

31. Adjimani JP, Asare P (2015) Antioxidant and free radical scavenging activity of iron chelators. Toxicol Rep 2:721-728 
32. Lü JM, Lin PH, Yao Q, Chen C (2010) Chemical and molecular mechanisms of antioxidants: experimental approaches and model systems. J Cell Mol Med 14(4):840-860

33. Afshari A, Sayyed-Alangi SZ (2016) Antioxidant effect of leaf extracts from Cressa cretica against oxidation process in soybean oil. Food Sci Nutr 5(2):324-333

34. Kanlayavattanakul $\mathrm{M}$, Ospondpant $\mathrm{D}$, Ruktanonchai $\mathrm{U}$, Lourith $\mathrm{N}$ (2012) Biological activity assessment and phenolic compounds characterization from the fruit pericarp of Litchi chinensis for cosmetic applications. Pharm Biol 50(11):1384-1390

35. Weecharangsan $W$, Opanasopit $P$, Sukma $M$, Ngawhirunpat $T$, Sotanaphun U, Siripong P (2006) Antioxidative and neuroprotective activities of extracts from the fruit hull of mangosteen (Garcinia mangostana Linn.). Med Princ Pract 15(4):281-287

36. Catalá A (2013) Five decades with polyunsaturated Fatty acids: chemical synthesis, enzymatic formation, lipid peroxidation and its biological effects. J Lipids 2013:710290

37. Devalaraja S, Jain S, Yadav H (2011) Exotic fruits as therapeutic complements for diabetes, obesity and metabolic syndrome. Food Res Int 44(7):1856-1865
38. Subramanian R, Subbramaniyan P, Raj V (2013) Antioxidant activity of the stem bark of Shorea roxburghii and its silver reducing power. Springerplus 2(1):28

39. Iloki-Assanga SB, Lewis-Luján LM, Lara-Espinoza CL, Gil-Salido AA, Fernandez-Angulo D, Rubio-Pino JL, Haines DD (2015) Solvent effects on phytochemical constituent profiles and antioxidant activities, using four different extraction formulations for analysis of Bucida buceras L. and Phoradendron californicum. BMC Res Notes 8:396

40. Loizzo MR, Pugliese A, Bonesi M, Tenuta MC, Menichini F, Xiao J, Tundis R (2016) Edible flowers: a rich source of phytochemicals with antioxidant and hypoglycemic properties. J Agric Food Chem 64(12):2467-2474

Publisher's Note Springer Nature remains neutral with regard to jurisdictional claims in published maps and institutional affiliations. 